\title{
EDUCAÇ̃̃O AMBIENTAL NO LIVRO DIDÁTICO BRASILEIRO*
}

Maria Glória de Faria Nunes dos Santos ${ }^{* *}$

\section{RESUMO}

Neste artigo, apresenta-se um estudo exploratório que tem por objetivo analisar a contribuição do livro didático para a educação ambiental brasileira. Para tal fim, foi feita análise de conteúdo dos livros-texto das disciplinas de História, Língua Portuguesa, Geografia e Ciências, da $4^{\mathrm{a}}$ série do ensino fundamental, relacionados nos guias do Programa Nacional do Livro Didático, do Ministério da Educação, referentes ao triênio 2004-2006. A maioria dos livros analisados apresenta elementos de educação ambiental, principalmente em relação às externalidades negativas do desenvolvimento, e muitos deles apontam para uma educação emancipatória, ética e planetária. Mas ainda não é possível afirmar que são instrumentos satisfatórios para a formação da cidadania ambiental ou para a implantação de um modelo sustentável de desenvolvimento.

Palavras-chave: Desenvolvimento sustentável. Cidadania. Ética. Planetaridade.

\section{INTRODUÇ̃̃o}

A publicação do livro Primavera silenciosa, de Rachel Carlson, em 1962, denunciando a vulnerabilidade dos pássaros ante os efeitos do DDT, e as conseqüentes reações dos fabricantes de defensivos agrícolas, torna-se um ponto de referência que evidencia, de forma marcante, a incompatibilidade entre a lógica capitalista e o meio ambiente. Estava, assim, eclodida uma crise ambiental sem precedentes, provocada pelo tipo de relações estabelecidas entre o homem, o desenvolvimento e seu ambiente natural.

\footnotetext{
* Artigo recebido em 4/02/2008 e aprovado em 30/05/2008.

** Mestre em Ciências da Educação. Diretora e coordenadora da Escola Maria Esméria, Piranhas-GO. E-mail: mgfnsantos@g8net.com.br
} 
Ainda nos anos 60, foi usada, pela primeira vez, a expressão educação ambiental, na conferência de educação, realizada na Universidade de Keele, na Grã-Bretanha, inaugurando-se uma trajetória de crescente interesse pelas transformações de comportamentos e valores éticos para se chegar à sustentabilidade do desenvolvimento.

Apesar de toda importância que a educação ambiental foi adquirindo a partir dos anos 60, legitimada pelas Nações Unidas, o livro didático não incorporou, no mesmo ritmo, como objeto de seus conteúdos, temas e formas de abordagem que contribuíssem para o enfrentamento da crise ambiental que se estabeleceu a partir do atual modelo de desenvolvimento, que subordina a vida humana a seus interesses.

Entre os objetivos fundamentais da Lei n. 9.795/99, que instituiu a Política Nacional de Educação Ambiental, incluídos em seu $5^{\circ}$ artigo, estão

- o desenvolvimento de uma compreensão integrada do meio ambiente em suas múltiplas e complexas relações, envolvendo aspectos ecológicos, psicológicos, legais, políticos, sociais, econômicos, científicos, culturais e éticos; e - o incentivo à participação individual e coletiva, permanente e responsável, na preservação do equilíbrio do meio ambiente, entendendo-se a defesa da qualidade ambiental como um valor inseparável do exercício da cidadania.

Dessa forma, o desenvolvimento de uma compreensão integrada do meio ambiente e o incentivo à participação permanente e responsável na preservação do equilíbrio ambiental, inseparável do exercício da cidadania, são objetivos a serem alcançados pela educação formal e não-formal, como reza o caput do $2^{\circ}$ artigo: "educação ambiental é um componente essencial e permanente da educação nacional, devendo estar presente, de forma articulada, em todos os níveis e modalidades do processo educativo, em caráter formal e não-formal".

Assim, a educação, num contexto de crise ambiental causada pelo paradigma ainda dominante, torna-se a grande esperança para o futuro, já que ela representa o local apropriado para a sociedade se reencontrar com a natureza e desenvolver valores e comportamentos ambientalmente éticos, tal como a responsabilidade perante o futuro (Hans Jonas apud Fernandes, 2004), numa profunda reeducação dos hábitos de consumo e de acumulação de bens, construindo uma sociedade com uma econo- 
mia solidária baseada na extensão de um modo de vida sustentável para todos.

\section{A MUDANÇA DE PARADIGMAS}

O modelo de racionalidade dominante na ciência moderna foi construído progressivamente desde o século XVI, tendo sido desenvolvido, nos séculos seguintes, sob a égide das ciências naturais. Dele resultou o paradigma científico dominante, que procura um conhecimento objetivo, racional, universal e determinista, constituindo uma ordem que admite uma única forma de conhecimento verdadeiro, denominado de conhecimento científico. A confiança quase absoluta na capacidade de previsão da ciência, que resulta na convicção de que a explicação e previsão de todos os fenômenos estão ao seu alcance, é sua principal característica, dela resultando seu caráter mecanicista (SANTOS, 1997).

Outro aspecto do paradigma dominante é seu caráter antropocentrista cujas raízes já se encontram no Velho Testamento, em Gênesis 2:26, onde se lê que o homem dominará todos os animais do mar, do céu, os domésticos, as feras e os que rastejam. Entretanto, o antropocentrismo tomará outras proporções a partir, principalmente, da lógica de Francis Bacon, importante componente na virada epistemológica que leva ao mundo mecânico e à ética antropocêntrica, e da filosofia de Descartes, cujo pensamento é o marco filosófico moderno em que se funda a predominância do homem sobre todas as coisas e criaturas do mundo (GRÜN, 2004).

Contudo, à medida que o conhecimento propiciado pelo paradigma dominante avança, vai mostrando a fragilidade de suas bases, e a ciência determinista vai sendo substituída por uma ciência probabilística. Dessa forma, vivemos uma época de transição paradigmática, em que o paradigma emergente, dentro de uma lógica relacional e auto-organizacional que leva o ser humano a redescobrir o lugar que lhe corresponde dentro do conjunto harmonioso do universo (SANTOS, 1997), requer "novas respostas em todos os âmbitos: político, econômico, cultural, educativo e outros" (GutiérRez; PrAdo, 2000, p. 30).

A partir da evidência de incompatibilidade de princípios entre capitalismo e sustentabilidade, ficou evidente que as soluções para os problemas globais não se reduzem apenas à prevenção da degradação do ambiente físico e biológico, mas incorporam dimensões sociais, po- 
líticas e culturais, como a pobreza e a exclusão social (BARBIERI, 2000, p. 15-16). Incluem, ainda, as dimensões econômica, ética e ambiental (GADOTTI, 2000, p. 57).

No sentido da economia, as maiores dificuldades estão ligadas à exclusão das condições ecológicas que asseguram a preservação das bases produtivas dos ecossistemas naturais nos projetos de desenvolvimento. Essas dificuldades decorrem de uma racionalidade econômica que não incorpora suas externalidades ambientais nem os princípios de um desenvolvimento sustentável, resultando, entre outros, altos e crescentes níveis de contaminação, aproveitamento irracional dos recursos energéticos, perda da fertilidade dos solos, aumento de áreas desertificadas, erosão de terras produtivas, aquecimento global... Assim, o processo econômico aparece como uma contradição entre conservação e desenvolvimento, fazendo com que a crise ambiental questione os "paradigmas da economia para internalizar as externalidades socioambientais geradas pela racionalidade econômica dominante" (LefF, 2000, p. 173-175, grifos nossos).

Junto com o processo de degradação ambiental, conjuga-se uma série de efeitos econômicos, sociais e culturais, os quais afetam as maiorias pobres. Assim, a desertificação ocasionou fome nos países africanos, a deterioração ambiental, junto com a crise financeira dos países da América Latina, agravou o processo de empobrecimento da população e a marginalização social. Estes processos de degradação ecológica e social estão associados com a expansão da fronteira agrícola para ecossistemas cada vez mais frágeis, e com a implantação de modelos tecnológicos inadequados para os trópicos. Estes projetos de colonização geraram processos migratórios e assentamentos precários, associados com o desemprego, a aglomeração, a insalubridade e a segregação social nas cidades, tendo provocado o desenraizamento das comunidades, a destruição de suas identidades culturais e o desuso de práticas tradicionais de utilização dos recursos. (LefF, 2000, p. 219-220)

O despertar da educação ambiental diante das novas mudanças teve, segundo Caride e Meira (2001), três fases distintas. A primeira, educar para conservar, incorpora objetivos de melhorar as relações ecológicas tanto do homem com a natureza como dos homens entre si e desenvolver atitudes e valores, como a construção de uma nova ética pessoal e social. A segunda, educar para conscientizar, compreende um 
período de transição iniciado com a Conferência Intergovernamental de Educação Ambiental de Tbilisi (Geórgia, 1977), onde se delinearam idéias e princípios básicos da educação ambiental, muitos ainda vigentes. E a terceira fase, educar para mudar, teve início a partir de 1987, com a publicação do Relatório Brundtland, também conhecido como Nosso Futuro Comum, que estabelece uma estreita relação entre os problemas ambientais e o modelo de desenvolvimento, reforçada pela Agenda 21, cujo capítulo 36 recomenda, entre outros, a reorientação da educação para o desenvolvimento sustentável e o aumento da consciência pública.

Mauro Guimarães (2004) sugere que a educação ambiental seja também crítica, contrapondo-a à educação ambiental conservadora, que, segundo o que defende, se alicerça numa visão de mundo focada nas partes, privilegiando uma delas, o ser humano, sobre as demais. Centrada na parte, esconde a totalidade em suas complexas relações, produzindo assim uma prática pedagógica objetivada no indivíduo e na transformação de seu comportamento - educação individualista e comportamentalista. Esse privilégio estabelece uma diferença hierarquizada que constrói a lógica da dominação. Nessa perspectiva, a realização da ação educativa é focada na terminalidade da ação, que compreende o conhecimento retido - a "educação bancária" de que fala Paulo Freire - e o indivíduo transformado. Supõe ainda que a sociedade seja o resultado da soma de seus indivíduos, que transformando os indivíduos se transforma a sociedade.

Segundo Guimarães, a educação ambiental crítica não é uma evolução conceitual de algo anteriormente conservador, mas uma contraposição a partir de um outro referencial teórico, que subsidia uma leitura de mundo mais complexa e instrumentalizada para uma intervenção que contribua no processo de transformação da complexa realidade socioambiental, onde a constituição da realidade é decorrente de um movimento dialético/dialógico, cuja interação de forças, seus conflitos e consensos estruturam essa realidade.

\section{O LIVRO DIDÁTICO}

Os livros didáticos têm ocupado um lugar de destaque ao longo da história da educação brasileira. Eles foram e continuam a ser verdadeiros suportes do planejamento e da execução das aulas na maioria das esco- 
las. O próprio Guia do Programa Nacional do Livro Didático - PNLD (2003, v. 1, p. 10) afirma que o livro didático brasileiro, ainda hoje, é uma das principais formas de documentação e consulta utilizadas por professores e alunos, terminando por influenciar o trabalho pedagógico e o cotidiano da sala de aula.

Tendo em conta que a educação contemporânea exige a relação permanente entre teoria e prática e que educar é, não apenas a transmissão de idéias e conhecimentos isolados, mas a sua inserção numa prática transformadora do real, é pela relação dialética entre teoria e prática que se tornam mais eficazes as aprendizagens.

Assim, se "a ação educativa não é algo que se dá naturalmente, permitindo a interiorização de valores e conteúdos, mas é um processo programado que pode mudar/conservar o presente e o futuro" (CARVALHO, 1992, p. 7), ela pode se constituir num instrumento útil de transformação do pensamento e de atitudes em relação à educação ambiental, minimizando a distância entre as teorias defendidas por educadores e ambientalistas e a cotidianidade vivida nas escolas - sua práxis -, dando, portanto, mais sentido à prática escolar. Sentido que, na acepção de Alicia Bárcena, ${ }^{1}$ é construído num fazer diário, numa relação pessoal e grupal onde a tomada de consciência ambiental cidadã só se dá por ação efetiva quando acompanhada de uma população organizada e preparada para conhecer e exigir seus direitos e exercer suas responsabilidades.

Nesse contexto, conhecendo o lugar de destaque ocupado pelo livro didático na educação brasileira, considerado como instrumento construtor de uma cultura nacional, é assaz importante que ele acompanhe as mudanças dos saberes-pilar dos novos paradigmas da pós-modernidade.

\section{Metodologia}

Para a realização destse trabalho, fizemos uma análise de conteúdo, fundamentada em Bardin, dos livros didáticos da $4^{\mathrm{a}}$ série do ensino fundamental, como um caminho para conhecer o que é veiculado aos alunos pelas disciplinas de História, Língua Portuguesa, Geografia e Ciências, a respeito da formação da nova consciência ambiental, tendo em conta os postulados pós-modernos que sustentam e apontam para um novo paradigma emergente (SANTOS, 1997).

Os livros selecionados fazem parte dos guias do PNLD, para o triênio 2004/2006, e são apresentados em coleções de $1^{\mathrm{a}}$ a $4^{\mathrm{a}}$ série. As 
obras listadas nos guias são aprovadas e selecionadas pelos técnicos do Ministério de Educação (MEC), das equipes da Secretaria de Educação Fundamental (SEF), do Fundo Nacional para o Desenvolvimento da Educação (FNDE), e de universidades (GuiA PNLD, v. 1, 2003, p. 9).

Durante o desenvolvimento desse trabalho, recortamos dos livros didáticos analisados todos os excertos relacionados aos objetivos da pesquisa, respeitando nossa proposta de realizar uma pesquisa qualitativa, sempre procurando seguir as orientações e os postulados dos autores que nos subsidiaram, e nos detendo com exclusiva atenção nos aspectos ambientais.

Para o levantamento dessas passagens foi elaborado um quadro referencial, indicador dos aspectos que seriam analisados. As categorias foram o resultado final de leituras e reflexões, o instrumento de busca para a explicitação de como está inserida a educação ambiental nos livros didáticos brasileiros.

O tema Educação Ambiental foi dividido em cinco categorias: natureza, planetaridade, cidadania, ética e legislação. A categoria natureza foi desdobrada em três subcategorias - elementos físicos, químicos e biológicos, ecossistema e desenvolvimento. A subcategoria desenvolvimento, por sua vez, foi subdividida em externalidades negativas e positivas.

Quando nos referimos aos livros pesquisados, optamos por usar um código de acordo com a disciplina e a ordem em que o livro didático aparece nos guias do PNLD. Assim, os livros de História foram marcados com a letra $\mathrm{H}$, seguida do respectivo número de ordem (1 a 7), já que selecionamos sete livros dessa disciplina. Vale o mesmo para as outras disciplinas, respeitadas a letra inicial e a quantidade de livros selecionada de cada disciplina. A equivalência entre o código e o respectivo livro didático consta no final deste trabalho, na bibliografia dos livros analisados.

\section{Resultados}

Durante a análise dos livros didáticos, eles foram agrupados por disciplina para facilitar a organização da pesquisa. Mas para que se tenha uma idéia geral do trabalho desenvolvido e dos resultados obtidos, optamos por considerá-los num único conjunto, fazendo as ressalvas necessárias quando for cabível. 
Analisamos ao todo 36 manuais, cerca de $40 \%$ dos livros listados nos guias do PNLD/MEC, distribuídos pelas diferentes editoras, e proporcional ao número de livros e ao nível de avaliação do ministério. Desse total, apenas três livros didáticos não se referiram ao meio ambiente de forma alguma: dois de Língua Portuguesa e um de Ciências. Entre os restantes - 33 manuais -, três deles fizeram apenas referências aligeiradas e superficiais, também dois de Língua Portuguesa e um de Ciências. Portanto, podemos afirmar que $83,33 \%$ dos livros analisados - 30 manuais - elegeram o meio ambiente para fazer parte de seus conteúdos: alguns como tema transversal, outros como parte do conteúdo principal.

Em relação ao local onde foram desenvolvidos conteúdos relacionados ao meio ambiente, menos de um quarto dos manuais, ou seja, $21,21 \%$, desenvolveram os conteúdos ou as atividades relacionadas ao meio ambiente apenas no final do livro didático. Esse aspecto é importante porque indica evolução na valorização da educação ambiental no currículo brasileiro, uma vez que as primeiras inserções foram feitas como um capítulo à parte no final do manual, e apenas na disciplina Ciências.

Quadro 1: Categorias presentes nos manuais analisados.

\begin{tabular}{|c|c|c|c|c|c|c|c|c|c|}
\hline \multirow[b]{4}{*}{ 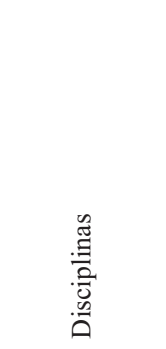 } & \multirow{4}{*}{ 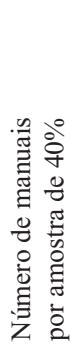 } & \multicolumn{8}{|c|}{ Categorias analisadas } \\
\hline & & \multicolumn{4}{|c|}{ Natureza } & \multirow[b]{3}{*}{ 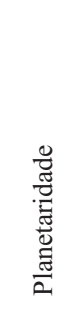 } & \multirow[b]{3}{*}{ 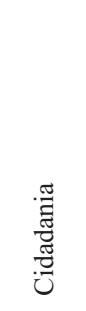 } & \multirow[b]{3}{*}{ : } & \multirow[b]{3}{*}{ 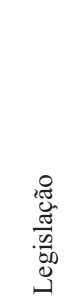 } \\
\hline & & \multirow{2}{*}{ 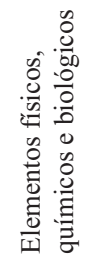 } & \multirow[b]{2}{*}{ 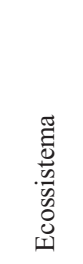 } & \multicolumn{2}{|c|}{ Desenvolvimento } & & & & \\
\hline & & & & 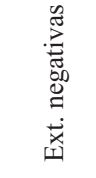 & 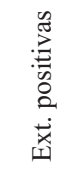 & & & & \\
\hline História & 7 & - & - & 7 & 3 & 1 & 4 & 3 & 2 \\
\hline L. Portuguesa & 12 & 2 & 5 & 10 & 5 & 3 & 7 & 6 & 1 \\
\hline Geografia & 8 & 4 & 4 & 8 & 6 & 2 & 8 & 4 & 4 \\
\hline Ciências & 9 & 4 & 6 & 8 & 7 & 4 & 7 & 6 & 3 \\
\hline Total & 36 & 10 & 15 & 33 & 21 & 10 & 26 & 19 & 10 \\
\hline$\%$ & 100 & 27,77 & 41,66 & 91,66 & 58,33 & 27,77 & 72,27 & 52,77 & 27,77 \\
\hline
\end{tabular}

Quanto às categorias analisadas, todos os livros didáticos que desenvolveram temas relacionados ao meio ambiente - 33 manuais, 91,66\% - abordaram as externalidades do desenvolvimento, principalmente as 
negativas. Cidadania, pelo viés ambiental, foi a segunda categoria mais abordada, ocorrente em $72,27 \%$ dos manuais, seguida de ética, abordada em $52,77 \%$. A seguir, vieram ecossistema, com $41,66 \%$ de ocorrências, e as três restantes - elementos físicos, químicos e biológicos, planetaridade e legislação -, cada uma ocorrente em $27,77 \%$ dos manuais.

Passamos, agora, a levantar relações mais amplas que podem ser estabelecidas entre o referencial teórico e os diferentes aspectos detectados nos conteúdos dos textos e exercícios analisados, extraindo os destaques, tanto pelos aspectos positivos como pelos negativos.

Morin (2002, p. 38) diz que o desenvolvimento próprio desta era planetária leva o homem a confrontar os desafios da complexidade cada vez mais e de maneira cada vez mais inelutável. Encontramos esse confronto em alguns livros didáticos analisados, numa abordagem transdisciplinar e ecológica, salientando as conseqüências nefastas do atual modelo de desenvolvimento, em termos ecológicos e sociológicos. ${ }^{2}$

São os carvoeiros [...] Seu suor está na carroceria dos automóveis, nas torres de transmissão que levam a luz para as residências, nas estruturas metálicas dos edifícios. (G4, p. 27)

É um dramático encontro entre dois mundos. De um lado a siderurgia moderna. De outro, uma devastação ambiental sem paralelo e condições de trabalho tão primitivas. (G4, p. 36)

Quais as razões do desaparecimento de algumas espécies de animais? Que problemas a extinção de animais silvestres ocasiona ao meio ambiente? (P7, p. 28)

Nos últimos anos a cidade cresceu muito; com isso, uma vasta área verde foi destruída para a construção de estradas, loteamentos e indústrias, fazendo com que muitas bicas e nascentes de pequenos riachos secassem. Para piorar, os principais rios que cortam a cidade estão contaminados pelo esgoto doméstico e industrial. (C7, p. 35)

Outras referências mostram as diferentes relações entre os componentes da natureza, como essas partes se inserem no todo, como funcionam dentro do sistema a que pertencem, como se encaixam nos ciclos e equilíbrios dinâmicos da natureza, numa referência implícita ao complexo, ao contexto, de modo multidimensional e dentro da concepção global (Morin, 2002, p. 39). 
São muitas as relações entre os seres vivos e destes com o ambiente. Os seres vivos precisam de alimentos. [...] Usando água, gás carbônico e a energia captada pela clorofila, a planta produz açúcar, pelo processo de fotossíntese. [...] A planta utiliza o açúcar produzido por ela. O que não utiliza, a planta armazena em forma de amido em suas diferentes partes: na raiz, no caule, nas folhas, e nas sementes. [...] Ao comerem as plantas, os animais ingerem o alimento que contém a energia necessária para a sua sobrevivência. A energia passa, então, da planta para o animal e deste para outro animal que dele se alimente. (C2, p. 10)

Você já estudou as cadeias alimentares. O que o surgimento das pragas tem a ver com as cadeias alimentares? [...] Quais as vantagens, para o homem e para o ambiente, em se utilizar o controle biológico? (C3, p. 72)

Mas o peixe-boi tem papel fundamental no seu ecossistema. Pelo fato de ser herbívoro, controla o crescimento das plantas aquáticas, ajudando a evitar a obstrução de rios e a poluição de praias. Outra característica importante é que suas fezes servem de adubo para o ecossistema aquático. (G7, p. 128)

No entanto, ainda caminhando nesta lenta transição entre comportamentos paradigmáticos, há referências que exemplificam as dificuldades das sociedades de economia capitalista neoliberal em equacionar a questão do desenvolvimento sustentável, como nestes excertos que indicam confiança na solução dos problemas ambientais quase que apenas por meio da ciência e da tecnologia. Em relação à questão dos resíduos, por exemplo, um dos maiores desafios da sustentabilidade dos ecossistemas, e da própria vida, poucos livros didáticos falaram na redução de consumo; pelo contrário, espera-se uma solução sobre o que fazer com o lixo produzido diariamente.

Quanto mais rico é um país, mais as pessoas que moram nele consomem. $\mathrm{E}$, quanto mais consomem, mais lixo produzem. Se não for tratado, esse lixo provocará grande males à natureza. (H4, p. 88)

Com o crescimento da população, da fabricação e da utilização de artigos industrializados (inclusive embalagens), a quantidade de lixo produzida é cada vez maior, tornando-se um sério problema para o meio ambiente. O que fazer com o lixo? (G8, p. 104)

Outras vezes, a realização da ação educativa é focada na terminalidade da ação, que compreende o conhecimento retido - referido como 
"educação bancária" por Paulo Freire - e o indivíduo transformado. Supõe, numa perspectiva simplista e reduzida de perceber uma realidade que é complexa, que a sociedade seja o resultado da soma de seus indivíduos, que transformando os indivíduos se transforma a sociedade.

Existem leis que proíbem as pessoas e as indústrias de poluírem o ar. É necessário fazer cumprir essas leis. Você pode ajudar a manter o ar limpo, denunciando quem polui. Lembre-se: você também é responsável! Estão poluindo o ar que você respira! (C1, p. 185)

Em outras abordagens, mesmo que mais à frente seja desenvolvido algum aspecto de proposta em educação ambiental naquele mesmo conteúdo, ainda predomina o caráter utilitarista da natureza (WoRTMANN; Teixeira; Veiga Neto, 1987, p. 68), trazendo implícita ou explicitamente padrões culturais advindos do antropocentrismo. Os excertos à frente, por exemplo, enfocam a existência da natureza em função da existência do homem.

O ar é indispensável aos seres vivos. Sem o oxigênio presente no ar seria impossível respirar. [...] O vento é o ar em movimento em certa direção. $\mathrm{O}$ ar é importante porque: movimenta embarcações e moinhos; espalha pólen e sementes; carrega a poluição; enche pneus de veículos, entre muitos outros usos que podemos fazer dele. (C9, p. 99)

Esses elementos, que a natureza demorou bilhões de anos para formar, transformaram-se em recursos naturais, atendendo às necessidades dos seres humanos. (G1, p. 19)

Nem sempre a preocupação com o esgotamento dos recursos naturais é em legítima defesa da vida, uma vez que pode revelar um comprometimento com as lógicas capitalistas, que se orientam pela defesa das condições de produção (GRÜN, 2004, p. 47).

O solo é de grande importância para o cultivo de vegetais, que servem de alimento para pessoas e animais. [...] Da crosta terrestre são extraídos materiais que os seres humanos transformam e utilizam para fabricar variados produtos. Esses devem ser reaproveitados ou substituídos por materiais que possam se renovar em pouco tempo, para evitar que se esgotem. (C6, p. 16-17) 
Muitos especialistas estão preocupados nos últimos anos com a utilização do petróleo em grandes quantidades. Essa preocupação deriva de dois argumentos:

- o petróleo é um recurso natural não renovável;

- a quantidade de petróleo no planeta é limitada e por isso ele pode acabar.

(C7, p. 77)

Contudo, neste contexto de transições, o processo incontrolável e insustentável de produção leva, muitas vezes, a racionalidade dominante a descobrir a complexidade de seus limites nas incertezas de um mundo economizado (LEFF, 2003, p.16).

Reduzir o consumo de mercadorias e de energia. Isso quer dizer: gastar menos água, energia elétrica, gás e combustíveis (gasolina, álcool, óleo diesel, etc.) e comprar só o que for realmente necessário. (C3, p. 140)

Não podemos deixar de lembrar, também, que vivemos em uma sociedade de consumo, ou seja, que procura incentivar as pessoas a estarem sempre comprando mercadorias, mesmo que elas não estejam precisando daqueles bens. [...] Quanto mais as pessoas consomem produtos industrializados, mais matéria-prima tem de ser retirada da natureza, mais energia tem que ser produzida. Parece um círculo vicioso. (G2, p. 120-121)

Ao escrever sobre as "áreas de silêncio" no currículo da educação moderna, Grün (2004, p. 110) cita a ausência de elementos que evidenciam as conseqüências do progresso nos sistemas naturais. No entanto, como foi mostrado em vários excertos recortados dos livros didáticos, pode-se observar a evolução nos conteúdos dos livros didáticos brasileiros nesse sentido, ou seja, há uma preocupação clara da grande maioria dos autores em mostrar o impacto do desenvolvimento nos sistemas naturais. Mas, como em toda transição, ainda persistem alguns "silêncios" nesse sentido, sendo o maior deles, detectado por nós, em relação à produção de energia provinda da biomassa. Outras áreas de silêncio detectadas foram em relação ao impacto ambiental pelas hidrelétricas, termelétricas e usinas nucleares; e em relação às condições quase desumanas de trabalho em carvoarias e lavouras de laranja e cana-de-açúcar.

Ao discorrer sobre as diferentes formas de produção de energia, alguns livros didáticos - C3, C6, C7, C9 e H6 - citaram a produção de álcool extraído da cana-de-açúcar, um recurso renovável que está substituindo a gasolina e o óleo diesel. Contudo, apenas um livro didático 
analisado, o de História, fez menção ao impacto tanto dos canaviais como das usinas produtoras de álcool nos sistemas naturais. Transcrevemos, a seguir, o excerto de apenas um exemplo deste tipo de área de silêncio, já que o conteúdo dos quatro manuais de Ciências referidos é muito semelhante; e o excerto do livro de História, que descreve o impacto ao meio ambiente.

Para [...] reduzir a necessidade de combustíveis como a gasolina e o óleo diesel [sic], os pesquisadores descobriram que a cana-de-açúcar pode fornecer o álcool, um combustível alternativo para os automóveis. O melhor dessa história é que a cana é uma fonte renovável de energia, pois pode ser plantada e colhida na quantidade que precisamos. Outro ponto é que o álcool, assim como sua queima para fazer os carros andarem, polui menos o ar do que a transformação do petróleo e a queima de combustíveis que derivam dele. (C3, p. 115)

O plantio e a produção do açúcar trazem sérios problemas ao meio ambiente e muitas vezes envolvem o desrespeito a alguns direitos humanos. [...] O primeiro passo para se formar um canavial era a derrubada da mata. A atividade canavieira foi responsável pela devastação de uma grande parte da mata atlântica [sic] brasileira. [...]

Infelizmente, as usinas são fontes poluidoras do meio ambiente, pois liberam gases na atmosfera. Alem disso, a maior parte dos resíduos da produção é despejada nos solos a uma temperatura muito alta, matando insetos e vermes. Por serem formados por substâncias ácidas, esses resíduos prejudicam também o solo e a água do subsolo.

A cana possui nas folhas espinhos muito pequenos que causam sérias irritações na pele. Para facilitar o trabalho dos cortadores, é ateado fogo no canavial. Então as folhas secas se queimam e as verdes e os caules são preservados. O problema é que, com a queimada, os animais (aves, répteis, insetos, vermes) e as plantas do local são mortos em minutos. A queima produz ainda uma fumaça escura e libera cinzas que o vento espalha por dezenas de quilômetros, acarretando, além da poluição, maior consumo de água para limpeza de quintais e ruas. (H6, p. 52-53)

Ainda em relação à produção de energia, encontramos outros textos que deixaram de ressaltar o impacto das hidrelétricas, termelétricas e usinas nucleares no meio ambiente. Foi o caso do livro C6, que afirmou que a "eletricidade é uma forma de energia que não causa poluição" (p. 112). Além de não citar o impacto causado pelos reservatórios das hidrelétricas, silenciou sobre a poluição causada pelas termelétricas, 
mesmo afirmando que elas "funcionam por meio do calor obtido com a queima de combustíveis, como o carvão e o petróleo", e sobre os riscos das usinas nucleares, "onde são empregados materiais radioativos como combustíveis" (p. 115).

Ainda detectamos a ausência de transversalidade, pelo viés ambiental, em textos que se referiram às más condições de trabalho. Foi o caso do livro P6, que não desenvolveu o tema meio ambiente em seus conteúdos, a não ser estas brevíssimas referências que transcrevemos abaixo. Mesmo mostrando o ambiente insalubre em canaviais, laranjais e carvoarias, só se falou do impacto que causa às crianças, já que o tema era trabalho infantil.

Os cortadores de cana ajudam a produzir o álcool dos automóveis e o açúcar que usamos em casa. [...] O corte de cana é um trabalho muito difícil. O trabalhador precisa de muita força nos braços e disposição para ficar o dia todo no sol, com as costas curvadas. Gilson, 16, [...] cortou cana desde os 13 e ainda reclama de dores no peito. (p. 76-77)

A exploração comercial infanto-juvenil nas carvoarias do Mato Grosso do Sul, na década de 90, chamou a atenção de ONGs, organizações não-governamentais, e autoridades governamentais pelos riscos à saúde das crianças trabalhadoras e pela característica de regime quase escravo (p. 86).

Grün (2004), fundamentado em Rolston III, ${ }^{3}$ chama a atenção para o uso do possessivo "nosso" em relação à natureza. Ele afirma que pode parecer bizarro este tipo de discussão, mas ela é importante na medida em que se discute o pensamento de que o homem não é apenas separado, mas dono da natureza. Nesse sentido, concordamos com seu modo de analisar e interpretar. O proprietário de um objeto pode se sentir no direito de dispor de sua propriedade conforme seu interesse imediato e sua responsabilidade com o outro ou com o futuro.

Assim, levantamos, nos recortes feitos nos livros didáticos pesquisados, todas as expressões que levaram a palavra nosso ou suas flexões: foram 16 "nosso planeta" e quatro "nosso país"; e mais "nossas paisagens", "nossa gente", "nosso ambiente", "nosso oxigênio", "nossos rios", "nossas florestas", "nossas fontes".

Além do possessivo "nosso", levantamos outras expressões que indicam uma situação de propriedade do homem em relação à natureza. Essas abordagens, que denotam o utilitarismo desta e a autonomia 
do homem, reforçam a idéia de que a natureza só existe em função da existência do homem. Esta postura decorre de uma visão positivista e antropocêntrica que influenciou fortemente a educação moderna, e, ainda que esporadicamente, flagramos sua presença nos livros didáticos deste início de século XXI.

Essa comparação mostra como a quantidade de água doce disponível para o nosso $u s o^{4}$ é pequena diante de toda a água existente na Terra. (P3, p. 121; P7, p. 67)

O total da água que existe no nosso planeta é mais ou menos constante, mas somente $1,4 \%$ dela é adequada para o consumo humano. (G1, p. 121)

Ao homem, porém, só interessa a água que pode ser utilizada para matar sua sede e para produzir alimentos. As outras são inúteis, pelo menos enquanto não existir uma tecnologia capaz de transformar a água do mar em água potável de forma economicamente viável. (G1, p. 124)

A parte que pode ser usada pelos seres vivos é muito pequena. Desses 100 litros, seria só 1 litro que temos disponível para nós: para beber, tomar banho, lavar roupa e cozinhar. (C4, p. 162)

A respeito dos problemas ambientais relacionados à pobreza, Strong (1994, p. 30) afirma que a pobreza obriga as pessoas a destruir e esgotar os recursos de que dependeriam para seu desenvolvimento futuro, para usá-los na sobrevivência imediata. É o caso dos assentamentos dos sem-terra, citado aligeiradamente em um dos livros didáticos analisados, e apenas em relação à Amazônia. Sabe-se, segundo estudos do Instituto do Homem e Meio Ambiente da Amazônia (Imazon), que é retirada, anualmente, da floresta, apenas por posseiros e assentados do Movimento dos Sem-Terra, uma fatia de 470.000 hectares. Estudos do Instituto Brasileiro de Geografia e Estatística indicam que as pequenas propriedades respondem por $18 \%$ das taxas oficiais de desmatamento.

Uma das formas de eles pressionarem o governo a lhes assegurar terra é realizando a invasão e a ocupação de fazendas em alguns estados. E algumas das áreas ocupadas ficam na Amazônia, onde, para plantar, é preciso desmatar... (G2, p. 111)

Em relação à referência ao desmatamento na Amazônia, pelos sem-terra, pode dar margem a que o aluno interprete que, se o desma- 
tamento fosse em outro lugar, não haveria maiores problemas, já que, praticamente, há assentamentos em todos os estados. O Cerrado, por exemplo, que ficou desprotegido pela Constituição de $1988,{ }^{5}$ porque na época havia grande incentivo federal para a expansão agropecuária no país, ${ }^{6}$ é o sistema ambiental brasileiro que mais sofreu alteração com a ocupação humana nos últimos anos. A exemplo da Amazônia, também deve parte dos desmatamentos sofridos às pequenas propriedades, entre elas, os assentamentos dos sem-terra.

Uma outra questão que merece ser enfocada é a atual política centralizadora que envolve o livro didático brasileiro, que parece ser um tanto audaciosa em um país com a dimensão territorial e as diferenças culturais e socioeconômicas encontradas no Brasil.

A própria Lei de Diretrizes e Bases da Educação Nacional estabelece que os currículos dos ensinos fundamental e médio devem ter uma base comum e uma parte dedicada às características da região onde está instalada a instituição escolar. No entanto, o que vemos é o predomínio do Sudeste em quase todos os livros didáticos. O Cerrado, a segunda maior formação vegetal brasileira, aparece em pouquíssimos textos, conforme constatamos no transcorrer da análise.

\section{CONSIDERAÇÕES FINAIS}

Temos consciência de que o livro didático não possui, por si só, força para determinar a formação de um cidadão ambiental, ético, responsável e cooperador com a vida do planeta Terra. No entanto, é impossível ignorar sua posição privilegiada de transmissor de conteúdos transversais, posição esta reforçada pelo papel que desempenha na metodologia e na qualidade das aulas desenvolvidas com os alunos, nas escolas públicas brasileiras.

Reafirmamos nossa posição de não absolutizar a influência do livro didático na formação de um indivíduo, porque acreditamos que os textos escolares são apenas um dos instrumentos formadores de uma determinada visão de mundo. Assim, não podem ter força maior que a realidade vivida. A prática da pedagogia da autonomia é exercida, segundo Paulo Freire, com a participação efetiva dos alunos na produção do conhecimento, com sentido, evidentemente. $O$ sentido da vida não vem de conhecimentos, informações e nem de verdades transmitidas por meio de textos, discursos ou leis. O sentido se tece a partir de relações 
imediatas, a partir de cada ser, a partir dos sucessivos contextos nos quais se vive.

No entanto, defendemos que o texto escolar deve dar elementos para que o aluno detecte as contradições básicas da realidade em que vive, e passe a trabalhar sobre elas na perspectiva de meios de produção e consumo mais ecológicos e de uma sociedade mais justa. Mas sabemos também que o aperfeiçoamento do livro didático é um caminho que precisa ser trilhado, mas não isoladamente.

Se o sistema educacional, com seus recursos pedagógicos, reflete um sistema político vigente numa sociedade, ele só poderá sofrer transformações substanciais se esta estrutura social também se modificar, num movimento dialético entre suas partes constitutivas.

Efetivamente, vivenciamos a atualização dos sistemas sociais para incluir a dimensão ambiental em suas respectivas áreas de atuação, fazendo com que realizem a transição social rumo à sustentabilidade. Dessa forma, cada sistema social caminha nessa direção: o sistema científico desenvolve uma ciência complexa; o sistema jurídico cria um direito ambiental; o sistema econômico potencializa uma economia ecológica; o sistema tecnológico procura uma tecnologia eco-eficiente; o sistema político desenvolve uma política verde; e o sistema educativo desenvolve uma educação ambiental.

Nesse contexto, onde os diversos sistemas sociais atuam na promoção da mudança do enfoque ambiental, a posição que a educação deve assumir é de construir os fundamentos da sociedade sustentável. Conseqüentemente, ela tem uma dupla função: propiciar os processos de mudanças culturais em direção à instauração de uma ética ecológica; e de tornar viáveis os processos de mudanças sociais rumo ao fortalecimento de pessoas, grupos e sociedades mais vulneráveis diante dos desafios da contemporaneidade. Aqui, o livro didático tem importância capital. Ainda mais sendo, para muitas crianças brasileiras, o único texto que se tem para ler e estudar.

O objetivo deste estudo era conhecer o nível de contribuição do livro didático para se efetivarem as mudanças culturais e sociais necessárias à construção de uma ética ecológica que propicie o desenvolvimento sustentável. Nos inúmeros recortes que fizemos, muitas vezes nos deparamos com a instabilidade dos autores, ora no velho paradigma dominante, ora no novo paradigma emergente. Contudo, concluímos que, a exemplo 
dos diferentes sistemas sociais, o livro didático brasileiro, de modo geral, caminha na direção da formação do cidadão ambiental.

$\mathrm{O}$ resultado deste estudo nos deixou otimistas em relação à evolução do livro didático brasileiro neste período de tantas transições, principalmente em se comparando com outros estudos realizados anteriormente, por outros pesquisadores, cujos resultados denotaram conquistas bem mais modestas, no sentido de propiciar a práxis da educação ambiental.

Lidar com educação ambiental implica tanto em resgatar como em construir valores, seja nas múltiplas relações no âmbito escola/comunidade, seja na eleição/construção dos conteúdos dos livros-texto, seja na própria política que envolve o livro didático brasileiro - tarefa complexa e difícil, mas não impossível.

\section{ABSTRACT}

The aim of this study is to analyze the contribution of textbooks to Brazilian environmental education. To do so, the contents of History, Portuguese, Geography and Science textbooks were analyzed. These books are prescribed by the Ministry of Education in its Guidelines for the Primary School Book Program for use in $4^{\text {th }}$ grade primary education, for the 2004 to 2006 period. Most of the books analyzed contain aspects of environmental education, particularly in relation to the negative externalities of development, and a large number of these books point towards an emancipating, ethical and planetary education. But it is not yet possible to say whether they are satisfactory instruments for the formation of environmental citizenship or the implementation of a model of sustainable development.

Keywords: Sustainable development. Citizenship. Ethics. Planetarity.

\section{NOTAS}

1. Alicia Bárcena. Apresentação. In: GutiÉrRez, Francisco; Prado, Cruz. Ecopedagogia e cidadania planetária. São Paulo: Cortez, 2000. p. 14.

2. As citações de excertos dos livros didáticos foram escolhidas aleatoriamente, sem nenhuma intenção de privilegiar ou prejudicar qualquer livro, autor ou editora. Muitas vezes, num mesmo livro, foram feitos recortes tanto de aspectos positivos como de negativos, numa demonstração de que a mudança de modelos paradigmáticos está em curso. 
3. H. Rolston III (1986). Philisophy gone wild: essays in environmental ethics. Buffalo: Prometheu Books.

4. Os grifos nesta seqüência de citações são nossos.

5. O capítulo IV, com o título "Meio Ambiente", art. 225, § 4", afirma que a "Floresta Amazônica brasileira, a Mata Atlântica, a Serra do Mar, o Pantanal Mato-Grossense e a Zona Costeira são patrimônio nacional, e sua utilização far-se-á, na forma da lei, dentro de condições que assegurem a preservação do meio ambiente, inclusive quanto ao uso dos recursos naturais".

6. Existe no Congresso Nacional uma proposta de emenda à Constituição - PEC $115 / 95$, que propõe modificar o parágrafo $4^{\circ}$ do art. 225 da Constituição Federal, incluindo o Cerrado na relação dos biomas considerados Patrimônio Nacional.

\section{REFERÊNCIAS}

BARBIERI, J. C. Desenvolvimento e meio ambiente: as estratégias de mudanças da Agenda 21. Petrópolis: Editora Vozes, 2000.

BARDIN, L. Análise de conteúdo. Lisboa: Edições 70, 1977.

CARIDE, J. A.; MEIRA, P. A. Educación ambiental y desarrollo humano. Barcelona: Editorial Ariel S. A., 2001.

CARVALHO, A. M. M. de. Pregadores de idéias, animadores de vontades: livros didáticos nos anos 1930/1940. 1992. Dissertação - (Mestrado em História), Pontifícia Universidade Católica de São Paulo.

FERNANDES, M. de F. O "princípio responsabilidade" de Hans Jonas: em busca dos fundamentos éticos da educação contemporânea. In: NASCIMENTO, Eunice et al. Da ética à utopia em educação. Porto: Edições Afrontamento, 2004.

FREIRE, P. Pedagogia do oprimido. Rio de Janeiro: Paz e Terra, 1992.

Pedagogia da autonomia: saberes necessários à prática educativa. São Paulo: Paz e Terra, 1996.

GADOTTI, M. Pedagogia da terra. São Paulo: Peirópolis, 2000.

GUIMARÃES, M. Educação ambiental crítica. In: LAYRARGUES, P. P. (Coord.). Identidades da educação ambiental brasileira. Brasília: MMA, 2004.

GRÜN, M. Ética e educação ambiental: a conexão necessária. Campinas, SP: Papirus, 2004. 
GUTIÉRREZ, F.; PRADO, C. Ecopedagogia e cidadania planetária. São Paulo: Cortez, 2000.

LEFF, E. Ecologia, capital e cultura: racionalidade ambiental, democracia participativa e desenvolvimento sustentável. Blumenau, SC: Ed. da FURB, 2000.

MORIN, E. Os sete saberes necessários à educação do futuro. São Paulo: Cortez, 2002.

SANTOS, B. de S. Um discurso sobre as ciências. Porto: Edições Afrontamento, 1997.

STRONG, M. F. Conferência de las Naciones Unidas sobre médio ambiente y desarrollo. In: GLENDER, A.; LINCHTGER, V. (Comp.). La Diplomacia Ambiental. México: Secretaria de Relaciones Exteriores/Fondo de Cultura Econômica, 1994. p. 19-44.

WORTMANN, M. L. C.; TEIXEIRA, C. M.; VEIGA NETO, A. J. Livros-texto de Ciências: uma análise preliminar. Educação \& Realidade. Porto Alegre: UFRGS, V. 12, n. 1, p. 65-70, 1987.

\section{LIVROS DIDÁTICOS ANALISADOS}

\section{História}

H-1 MARIN, M. F.; QUEVEDO, J.; ORDOÑEZ, M. Horizontes: História com reflexão - $4^{a}$ série. São Paulo: IBEP, 2001.

H-2 DREGUER, R.; MARCONI, C. História, 4a série. São Paulo: Moderna, 2003.

H-3 CHIANCA, R. B.; TEIXEIRA, F. M. P. Pensar e viver: História, $4^{a}$ série. São Paulo: Ática, 2003.

H-4 FERREIRA, J. R. M. et al. Primeiras noções de história, 4a serie. São Paulo, FTD, 2001.

H-5 SOURIENT, L.; RUDEK, R.; CAMARGO, R. História: interagindo e percebendo o mundo, $4^{\mathrm{a}}$ série. São Paulo: Ed. do Brasil, 2001.

H-6 VESENTINI, J. W.; MARTINS, D.; PÉCORA, M. Vivência e construção: História, $4^{a}$ série. São Paulo: Ática, 2001.

H-7 LUCCI, E. A. e BRANCO, A. L. Viver e Aprender: História, $4^{\mathrm{a}}$ série. São Paulo: Saraiva, 2003.

\section{Língua Portuguesa}

P-1 SILVA, A. de S.; BERTOLIN, R.; OLIVEIRA, T. A. Linguagem e vivência: Língua Portuguesa, $4^{a}$ série. São Paulo: IBEP, 2001. 
P-2 GOMES, S. Vitória-régia: Língua Portuguesa, 4a série. Campina Grande do Sul: Lago, 2001.

P-3 SOARES, M. Uma proposta para o letramento: Português, Livro 4. São Paulo: Moderna, 1999.

P-4 ESPESCHIT, R.; FERNANDES, M.; GUALBERTO, I. T. Português na ponta do lápis... e da Língua, Volume 4. Belo Horizonte: Dimensão, 2001.

P-5 CÓCCO, M. F.; HAILER, M. A. Análise, linguagem e pensamento - ALP Novo, $4^{\mathrm{a}}$ série. São Paulo: FTD, 2000.

P-6 PUNTEL, L.; OLIVEIRA, F. C. Curumim: Língua Portuguesa, $4^{\mathrm{a}}$ série. São Paulo: Atual, 2001.

P-7 CIPRIANO, L. H. R.; WANDRESEN, M. O. L. Linhas \& entrelinhas: Língua Portuguesa, $4^{\mathrm{a}}$ série. Curitiba: Nova Didática, 2000.

P-8 GIANINI, E. B.; GUALASSI, M. S. A.; PRIOLI, M. M. S. Leitura, Interação e Produção - LIP: Trabalhando com projetos, $4^{\mathrm{a}}$ série. São Paulo: Ed. do Brasil, 2001.

P-9 PASSOS, C.; SILVA, Z. Eu gosto de Língua Portuguesa: prática da linguagem escrita e oral, $4^{\text {a }}$ série. São Paulo: Nacional, 2001.

P-10 MATOS, M. D. Na trilha do texto, $4^{\mathrm{a}}$ série. São Paulo: Quinteto Editorial, 2001.

P-11 CORREA, M. H.; PONTAROLLI, B. S. M. Novo tempo: Português, $4^{\mathrm{a}}$ série. São Paulo: Scipione, 2001.

P-12 MIRANDA, C.; RODRIGUES, M. L. D. Pensar e viver: Língua Portuguesa, $4^{\mathrm{a}}$ série. São Paulo: Atica, 2001.

\section{Geografia}

G-1 CASTELAR, S.; ZAMBONI, E. Curumim: Geografia, 4ª série. São Paulo: Atual, 2001

G-2 CRUZ, M.; FILIZOLA, R.; COLLODEL, V. O mundo em movimento: a construção das paisagens brasileiras, $4^{\mathrm{a}}$ série. Curitiba: Nova Didática, 2001.

G-3 DURIN, A; MEDEIROS, I. Vitória-Régia: Geografia, 4ª série. Campina Grande do Sul: Lago, 2001.

G-4 LINS, A. L. Tantos lugares... tantas pessoas: Geografia, $4^{\mathrm{a}}$ série. São Paulo: FTD, 2001.

G-5 GARCIA, W. A escola é nossa, 4a série. São Paulo: Scipione, 2001.

G-6 SOURIENT, L.; RUDEK, R.; CAMARGO, R. Interagindo e percebendo o mundo: Geografia, $4^{\mathrm{a}}$ série. São Paulo: Ed. do Brasil, 2001. 
G-7 VESENTINI, J. W.; MARTINS, D.; PÉCORA, M. Vivência e construção: Geografia, 4a série. São Paulo: Ática, 2001.

G-8 LUCCI, E. A.; BRANCO, A. Viver e aprender: Geografia, $4^{\mathrm{a}}$ série. São Paulo: Saraiva, 2001.

\section{Ciências}

C-1 SAMPAIO, F. A.; CARVALHO, A. F. de Caminhos da ciência: uma abordagem socioconstrutivista, $4^{\mathrm{a}}$ série. São Paulo: IBEP, 2001.

C-2 MACHADO, A. M. Ediouro: Ciências, $4^{\mathrm{a}}$ série. São Paulo: Ediouro, 2001.

C-3 LAGO, S. R.; MEIRELLES, E. Vitória-régia: Ciências, 4ª série. São Paulo: IBEP, 2003.

C-4 LEMBO, R.; COSTA, I. Pensar e viver: Ciências, $4^{a}$ série. São Paulo: Ática, 2001.

C-5 NIGRO, R. G.; CAMPOS, M. C. Vivência e construção: Ciências, $4^{\mathrm{a}}$ série. São Paulo: Ática, 2003.

C-6 PEIXOTO, M. L.; ZATTAR, S. M.; KAMEYAMA, V. L. Bom tempo: Ciências Naturais, $4^{\mathrm{a}}$ série. São Paulo: Moderna, 2003.

C-7 CUNHA, P.; RAIMONDI, S. Curumim: Ciências, $4^{\mathrm{a}}$ série. São Paulo: Atual, 2001.

C-8 TRIVELATO, S. et al. Na trilha da ciência, $4^{a}$ série. São Paulo: Quinteto Editorial, 2001.

C-9 OLIVEIRA, E. C. de.; GONÇALVES, M. da P. Rosa dos ventos: Ciências Naturais, $4^{\text {a }}$ série. São Paulo: Moderna, 2003.

\section{Guia PNLD}

NADAI, E. (Coord.). Guia de livros didáticos, $1^{a} a 4^{a}$ série: Língua Portuguesa e Alfabetização, v. 1. Brasília: MEC, 2003.

NADAI, E. (Coord.). Guia de livros didáticos, $1^{a} a 4^{a}$ série: Matemática e Ciências, v. 2. Brasília: MEC, 2003.

NADAI, E. (Coord.). Guia de livros didáticos, $1^{a} a 4^{a}$ série: Geografia e História, v. 3. Brasília: MEC, 2003. 